\title{
European public health policies for managing contacts of invasive meningococcal disease cases better harmonised in 2013 than in 2007
}

S Vygen ${ }^{12}$, W Hellenbrand ${ }^{3}$, P Stefanoff ${ }^{4}$, G Hanquet ${ }^{5}$, S Heuberger ${ }^{6}$, J Stuart ${ }^{7}$

1. French Institute of Public Health Surveillance, Department of Coordination of Alerts and Regions, Regional office in Aquitaine, Bordeaux, France

2. European Programme for Intervention Epidemiology Training (EPIET), European Centre for Disease Prevention and Control (ECDC), Stockholm, Sweden

3. Department of Epidemiology, Robert Koch-Institut, Berlin, Germany

4. Department of Infectious Disease Epidemiology, National Institute of Public Health, Oslo, Norway

5. Consultant epidemiologist (independent), Brussels, Belgium

6. Meningococcal Reference Laboratory, Austrian Agency for Food and Health Safety, Graz, Austria

7. University of Bristol, Bristol, United Kingdom

Correspondence: Sabine Vygen (vygens@rki.de)

Citation style for this article:

Vygen S, Hellenbrand W, Stefanoff P, Hanquet G, Heuberger S, Stuart J. European public health policies for managing contacts of invasive meningococcal disease cases better harmonised in 2013 than in 2007. Euro Surveill. 2016;21(5):pii=30125. DOI: http://dx.doi.org/10.2807/1560-7917.ES.2016.21.5.30125

Article submitted on 23 September 2014 / accepted on 07 May 2015 / published on 04 February 2016

In 2007, a European survey identified variation in country policies on public health management of invasive meningococcal disease (IMD). In 2009-10, the European Centre for Disease Prevention and Control (ECDC) published evidence-based guidance on IMD. We therefore surveyed again European countries to describe policies for managing IMD cases and contacts in 2013. We asked national IMD public health experts from 32 European countries to complete a questionnaire focusing on post-exposure prophylaxis (PEP) for IMD contacts and meningococcal vaccination. Proportions in 2007 and 2013 were compared using the chi-squared test. All 32 countries responded, with responses from two regions for Belgium and Italy; half stated having used ECDC guidance to update national recommendations. PEP was recommended to close contacts in 33 of 34 countries/regions, mainly ciprofloxacin for adults (29/32 countries) and rifampicin for children (29/32 countries). ECDC guidance for managing IMD contacts in airplanes was strictly followed by five countries/regions. Twenty-three countries/regions participated in both surveys. Compared with 2007, in 2013, more countries/regions recommended i) ceftriaxone for children (15/23 vs 6/20; $p=0.03$ ), ii) PEP for all children in the same preschool group (8/23 vs $17 / 23 ; p=0.02)$. More countries/regions recommended evidence-based measures for IMD public health management in 2013 than 2007. However, some discrepancies remain and they call for further harmonisation.

\section{Introduction}

Invasive meningococcal disease (IMD) is associated with high case fatality ( $9 \%$ in 26 European countries in 2011 [1]) and substantial risk of long-term sequelae among survivors [2-4]. This explains the high level of concern associated with cases of IMD despite a low incidence in Europe of under one case per 100,000 population annually in the past decade $[4,5]$. Close contacts of IMD patients have a 200- to 1,200-fold increased risk of developing the disease [6-9]. Post-exposure prophylaxis (PEP) and, in case of a vaccine-preventable strain in the index case, vaccination of close contacts, are evidence-based measures to reduce the risk of secondary IMD cases. However, while the former is based on direct evidence showing decreased incidence among household contacts if they receive PEP [10], the latter rests on indirect evidence only, consisting of the observed increased risk for IMD in household contacts despite chemoprophylaxis during the 14 to 365 days after contact with the index case $[7,11]$. A survey in 2007, performed by the public health management working group of the European Meningococcal Disease Society (EMGM), documented that recommendation of these and other public health control measures varied widely among European countries [12]. This heterogeneity was thought to reflect uncertainty on effectiveness of public health measures, but also pragmatic, economic or legal constraints of policymakers in different countries.

A consistent and evidence-based public health policy on the management of IMD cases and their contacts across Europe is desirable to facilitate communication among countries in case of cross border case management. Therefore, the EMGM working group developed evidence based guidance for good practice in public health management of sporadic cases of meningococcal disease and their contacts [10]. In 2010, 
ECDC guidance on public health management of sporadic cases of invasive meningococcal disease ${ }^{\mathrm{a}}$ and risk assessment of infectious diseases transmitted on aircraft ${ }^{\mathrm{b}}$

\section{ECDC guidance}

- Chemoprophylaxis with an antibiotic regimen that eradicates carriage is recommended for household contacts of a case of IMD. (Strong recommendation)

- Sharing drinks, cigarettes or similar contact (implying a low level of salivary contact) with a case of IMD is not in itself an indication for chemoprophylaxis. (Weak recommendation)

- Attending the same preschool as a case of IMD is an indication for chemoprophylaxis, depending on risk assessment. (Weak recommendation)

- Attending the same school/college (including the same class) as a case of IMD is not in itself an indication for chemoprophylaxis. (Weak recommendation)

- Sharing the same transport vehicle as a case of IMD is not, in itself, an indication for chemoprophylaxis. (Weak recommendation)

- Rifampicin, ciprofloxacin, ceftriaxone, azithromycin and cefixime can be advised for chemoprophylaxis. (Strong recommendation) Ciprofloxacin, azithromycin and ceftriaxone are preferred. (Weak recommendation) In children, all these antibiotics can be advised. (Strong recommendation) In pregnant women, ceftriaxone, azithromycin and cefixime can be advised. (Weak recommendation)

- If a case of meningococcal disease is caused by a strain that is preventable by an available licensed vaccine, an appropriate course of vaccination - in addition to chemoprophylaxis - is recommended for household contacts unless considered to be protected by previous vaccination. (Strong recommendation)

\section{RAGIDA}

- Besides fellow travellers who may be household (-like) contacts of an index case, passengers and crew with close contact to pharyngeal secretions should be considered for contact tracing.

- Close contacts of IMD cases should be traced if the index cases were travelling while infectious (seven days before the onset of symptoms; up to 24 hours after the onset of effective treatment).

ECDC: European Centre for Disease Prevention and Control; IMD: invasive meningococcal disease; RAGIDA: risk assessment of infectious diseases transmitted on aircraft.

a Source: [10].

b Source: $[13,14]$.

Grading of Recommendations Assessment, Development and Evaluation (GRADE) [23] was used for ECDC guidance on public health management of IMD, but not in RAGIDA. this document was adopted as European Centre for Disease Prevention and Control (ECDC) guidance [10]. In addition, in 2009-10, risk assessment guidelines for diseases transmitted on aircraft (RAGIDA) including recommendations on the management of contacts to an IMD case were published by ECDC [13,14] (Box). The EMGM working group repeated the survey on IMD public health policies in 2013. Our objectives were to describe current public health policies for managing cases of meningococcal disease and their contacts in European countries, to track changes in national public health policies since 2007 and to assess to what extent measures outlined in the ECDC guidance were implemented in the respective countries.

\section{Methods}

We conducted a cross-sectional study, addressing 32 national IMD public health experts from all 28 European Union (EU) Member States and four European Free Trade Association (EFTA) countries (Iceland, Liechtenstein, Norway, and Switzerland). Participants from national public health institutes were identified from the previous survey in 2007 and from member lists of the ECDC Vaccine Preventable Diseases Network and EMGM. We invited potential participants via email to complete either a word or a web-based version (voozanoo by Epiconcept) of a structured questionnaire. The questionnaire comprised 40 questions and covered the following topics: clinical and laboratory diagnostic case definition criteria for confirmation of a case; the definition of a close contact for control measures; the use and choice of PEP for persons with contact to IMD cases in different settings; the use of meningococcal vaccines in routine schedules and after exposure to an IMD case; the perceived usefulness of the ECDC guidance document in updating national recommendations. The questionnaire was similar to the one used in 2007, but questions on criteria for defining cases and contacts and on policies for managing contacts in school and day care settings as well as in transport vehicles were expanded (questionnaire available from the authors upon request). Comparison of answers between 2007 and 2013 was restricted to countries participating in both surveys. Countries with missing data for a particular item were excluded when calculating proportions. Proportions were compared using chi-squared and Fisher's exact tests. Differences were considered statistically significant at $p<0.05$.

\section{Results}

All 32 countries responded to the 2013 survey. Two responses each were obtained from Belgium and Italy, reflecting sub-national policies. These were included as separate entities in the analysis, bringing the total number of respondents to 34 . The following 23 of the 34 countries/regions responded to both surveys: Austria, Belgium (Flanders and Wallonia), Czech Republic, Denmark, Estonia, Finland, France, Germany, Hungary, Iceland, Ireland, Lithuania, Malta, the Netherlands, Norway, Poland, Romania, Slovakia, Spain, Sweden, Switzerland, and the United Kingdom (UK). 
Criteria for definition of IMD cases for the purpose of control measures in 2007 and 2013, European survey on public health policies for managing cases of meningococcal disease and their contacts, 2013

\begin{tabular}{|c|c|c|c|c|}
\hline \multirow[t]{2}{*}{ Case definition criteria } & \multirow{2}{*}{$\begin{array}{c}\text { Countries/regions applying } \\
\text { criteria in } 2013(N=34) \\
n\end{array}$} & \multicolumn{2}{|c|}{$\begin{array}{c}\text { Countries/regions responding to both surveys } \\
\text { and applying criteria } \\
2007(\mathrm{~N}=23) \text { and } 2013(\mathrm{~N}=23)\end{array}$} & \multirow{2}{*}{$\begin{array}{l}\text { P value for } \\
\text { comparison } \\
2007 \text { Vs } 2013\end{array}$} \\
\hline & & $n(2007)$ & n (2013) & \\
\hline $\begin{array}{l}\text { Isolation of Neisseria meningitides from } \\
\text { sterile site }\end{array}$ & 34 & 22 & 23 & 1.000 \\
\hline $\begin{array}{l}\text { Isolation of meningococcal DNA from } \\
\text { sterile site }\end{array}$ & 32 & 20 & 22 & 0.608 \\
\hline Isolation of antigen from CSFa & 32 & 19 & 21 & 0.665 \\
\hline $\begin{array}{l}\text { Isolation of gram negative diplococci } \\
\text { from sterile site }\end{array}$ & 30 & 20 & 19 & 0.608 \\
\hline $\begin{array}{l}\text { Detection of high titre in convalescent } \\
\text { serum }\end{array}$ & 2 & 6 & 2 & 0.243 \\
\hline Clinically compatible & 21 & 16 & 13 & 0.542 \\
\hline Purpura fulminans & 24 & 16 & 15 & 1.000 \\
\hline Official notification & 15 & 12 & 9 & 0.554 \\
\hline
\end{tabular}

CSF: cerebrospinal fluid; IMD: invasive meningococcal disease.

European Centre for Disease Prevention and Control (ECDC) or risk assessment guidelines for diseases transmitted on aircraft (RAGIDA) recommendations are highlighted in grey.

a This criterion differed slightly in the 2007 questionnaire: 'Isolation of meningococcal antigen from sterile site'.

\section{Case definition criteria}

There were only slight changes between 2007 and 2013 for laboratory and other case definition criteria (Table 1). The only case definition criterion for laboratory diagnosis used by all countries in 2013 was 'isolation of Neisseria meningitidis from sterile site', but a high proportion also used 'isolation of meningococcal DNA from a sterile site', 'meningococcal antigen from CSF' and 'gram-negative diplococci from sterile site'.

\section{Definition of close contacts}

In 2013, 33 of 34 countries/regions recommended PEP to close contacts of an IMD case. This included all 23 countries/regions that also participated in the 2007 survey, when all respondents recommended PEP for close contacts after an IMD case (22/22; data missing for one country). However, the definition of close contact varied across countries/regions, with 11 of 34 countries/regions including sharing cups and glasses with an index case and 23 of 34 kissing on the mouth (Table 2). The maximum period after contact with a case in which initiation of PEP was recommended varied from seven days $(n=9 / 33)$ to one month $(n=5 / 33)$ (median 10 days; IQR 8-14).

\section{Recommended chemoprophylaxis}

Of the 33 countries/regions recommending PEP for close contacts of an IMD case in 2013, only one did not have specific guidelines on the choice of antibiotic for PEP. As in the 2007 survey, the most commonly recommended antibiotic in non-pregnant adults was ciprofloxacin (Table 3), most frequently administered as either $500 \mathrm{mg}(26 / 29)$ or $750 \mathrm{mg}(3 / 29)$, usually as a single dose (27/29), followed by rifampicin (usually as four $600 \mathrm{mg}$ doses (26/27)). From 2007 to 2013 , the proportion of countries/regions recommending use of ceftriaxone and azithromycin increased, but not significantly (Table 3). In 2013, 29 of 34 countries/regions recommended PEP during pregnancy, most commonly intramuscular ceftriaxone (Table 3). One country additionally recommended cefixime in pregnancy and for children.

Most countries/regions recommended rifampicin as PEP for one year-old children both in 2007 and 2013 (Table 3). Ciprofloxacin was recommended for this age in nine of 32 countries/regions in 2013 (starting from birth (4/9) or from one month (2/9) of age; the remaining three countries did not specify a minimum age). In addition, two countries recommended ciprofloxacin in older children, one starting from the age of two and the other from the age of 14 years. The only statistically significant change from 2007 to 2013 was an increase in the proportion of countries/regions recommending ceftriaxone for one year-old children (Table 3).

A few countries/regions additionally recommended antibiotics not included in the guidance for various target groups, namely spiramycin (2/34), penicillin (4/34), cotrimoxazole (1/34) and ofloxacin (1/34).

\section{Settings}

In 2013, 32 of 34 countries/regions reported specific policies for PEP in preschool and school settings and 33 of 34 in university settings. Twenty-two of 32 countries/regions recommended prophylaxis for all children sharing the same classroom following the occurrence of an IMD case in preschool. This increased significantly 


\section{TABLE 2}

Criteria for definition of close contacts of IMD cases for the purpose of control measures in 2007 and 2013, European survey on public health policies for managing cases of meningococcal disease and their contacts, 2013

\begin{tabular}{|c|c|c|c|c|}
\hline \multirow[t]{2}{*}{$\begin{array}{l}\text { Definition of close } \\
\text { contacts }\end{array}$} & \multirow{2}{*}{$\begin{array}{l}\text { Countries/regions applying } \\
\text { criterion in } 2013(\mathrm{~N}=34) \\
\mathrm{n}\end{array}$} & \multicolumn{2}{|c|}{$\begin{array}{c}\text { Countries/regions responding to both surveys and } \\
\text { applying criterion in } \\
2007(\mathrm{~N}=23) \text { and } 2013(\mathrm{~N}=23)\end{array}$} & \multirow[t]{2}{*}{$\begin{array}{c}\text { P value for comparison } \\
2007 \text { VS } 2013\end{array}$} \\
\hline & & $\mathrm{n}(2007)$ & n (2013) & \\
\hline $\begin{array}{l}\text { People sharing the } \\
\text { same household }\end{array}$ & 34 & 23 & 23 & 1.0 \\
\hline $\begin{array}{l}\text { People with } \\
\text { equivalent level of } \\
\text { close contact }\end{array}$ & 30 & 22 & 22 & 1.0 \\
\hline $\begin{array}{l}\text { Attending the same } \\
\text { preschool facility }^{a}\end{array}$ & 28 & NA & NA & NA \\
\hline Kissing on mouth & 23 & 20 & 15 & 0.17 \\
\hline $\begin{array}{l}\text { People sharing cups } \\
\text { and glasses }\end{array}$ & 11 & 9 & 5 & 0.34 \\
\hline Kissing on cheek & 4 & 3 & 1 & 0.61 \\
\hline \multicolumn{5}{|c|}{ Period in which index patient is considered infectious } \\
\hline $\begin{array}{l}7 \text { days before onset } \\
\text { of illness }\end{array}$ & 21 & 14 & 14 & 1.0 \\
\hline $\begin{array}{l}10 \text { days before } \\
\text { onset of illness }\end{array}$ & 10 & 7 & 8 & 1.0 \\
\hline
\end{tabular}

ECDC: European Centre for Disease Prevention and Control; IMD: Invasive meningococcal disease; NA: not applicable; RAGIDA: Risk assessment guidelines for diseases transmitted on aircraft.

ECDC or RAGIDA recommendations are highlighted in grey.

a This criterion was not included in the 2007 questionnaire.

\section{TABLE 3}

Choice of post-exposure prophylaxis for contacts of IMD cases in different target groups, European survey on public health policies for managing cases of meningococcal disease and their contacts, 2013

\begin{tabular}{|c|c|c|c|c|c|}
\hline \multirow[t]{2}{*}{ Target group } & \multirow[t]{2}{*}{ Antibiotic } & \multirow{2}{*}{$\begin{array}{l}\text { Countries/regions } \\
\text { recommending the antibiotic in } \\
2013(N=34) \\
n\end{array}$} & \multicolumn{2}{|c|}{$\begin{array}{c}\text { Countries/regions responding to both surveys } \\
\text { and recommending the antibiotic } \\
2007(\mathrm{~N}=23) \text { and } 2013(\mathrm{~N}=23)\end{array}$} & \multirow{2}{*}{$\begin{array}{l}\text { P value for } \\
\text { comparison } \\
2007 \text { vS } 2013\end{array}$} \\
\hline & & & n (2007) & n (2013) & \\
\hline \multirow{3}{*}{ Adults } & Ciprofloxacin & 29 & 20 & 21 & 1.0 \\
\hline & Rifampicin & 27 & 14 & 19 & 0.30 \\
\hline & Ceftriaxone & 22 & 13 & 15 & 0.76 \\
\hline \multirow{4}{*}{$\begin{array}{l}\text { Children of one } \\
\text { year of age }\end{array}$} & Ciprofloxacin & 9 & 5 & 7 & 0.75 \\
\hline & Rifampicin & 29 & 16 & 20 & 0.69 \\
\hline & Ceftriaxone & 21 & 6 & 15 & 0.03 \\
\hline & Azithromycin & 6 & 3 & 4 & 1.0 \\
\hline \multirow{3}{*}{$\begin{array}{l}\text { Women in the } \\
\text { first trimester } \\
\text { of pregnancy }\end{array}$} & Ciprofloxacin & 2 & 0 & 2 & 0.49 \\
\hline & Rifampicin & 3 & 4 & 3 & 0.69 \\
\hline & Azithromycin & 5 & 2 & 5 & 0.42 \\
\hline
\end{tabular}

ECDC: European Centre for Disease Prevention and Control; IMD: invasive meningococcal disease; PEP: post-exposure prophylaxis.

${ }^{a}$ Number of countries that recommended specifically certain antibiotics for PEP in pregnancy in $2013: \mathrm{n}=27 / 34$ (79\%). In $2007 \mathrm{n}=18 / 23 \mathrm{vS}$ $\mathrm{n}=20 / 23$ in 2013

ECDC recommendations are highlighted in grey. 
from 2007 to 2013 in countries participating in both surveys (Table 4). In school and university settings, most countries/regions recommended PEP only to close contacts within the class (Table 4).

In 2013, 20 of 32 countries/regions recommended PEP to contacts after an IMD case on a plane either in general or under specific circumstances (e.g. sitting next to the case, travel of a certain duration, overnight travel), a non-significant increase compared with 2007 (Table 5). In 2013, of the 20 countries/regions that recommended PEP after the occurrence of an IMD case on an aircraft, one implemented contact tracing for all passengers and 14 only for persons they considered eligible for PEP (Table 5). Five countries strictly followed the criteria recommended by RAGIDA. Fifteen of 31 countries/regions recommended PEP to contacts after an IMD case on a train or bus.

\section{Vaccination}

In 2007 eight of 23 countries recommended meningococcal serogroup $C$ vaccination in their national childhood vaccination programme, compared with 11 of 23 in 2013. Of all respondents to the 2013 survey $(n=34)$, 18 countries/regions recommended serogroup $C$ vaccination in their routine schedule. Of these, five recommended vaccination starting in the first six months of life and 13 at 12 months of age and older. Six countries/ regions recommended a booster dose for adolescents.

Vaccination of household contacts after the occurrence of an IMD case due to a vaccine-preventable serogroup was recommended by 24 of 34 countries/ regions in 2013. Among countries participating in both surveys, this increased slightly from 2007 (15/22) to $2013(17 / 22 ; p=0.46)$. Of the 24 countries/regions recommending post-exposure vaccination in 2013, seven recommended this for close contacts after a serogroup C IMD case and 15 after an IMD case due to serogroups $A, C, W$ or $Y$; serogroups were not specified by two countries. Countries/regions with meningococcal $C$ vaccination in their childhood immunisation schedule were somewhat more likely to recommend post-exposure vaccination $(14 / 18)$ than countries/regions not having a routine childhood meningococcal vaccination policy $(8 / 16, p=0.15)$.

\section{Perceived usefulness of ECDC guidance}

Twenty-eight of 31 countries/regions found the ECDC guidance [12] document useful. Half (17/34) reported having used the ECDC guidance to update recommendations in their country/region. The following topics were indicated as helpful: choice of medication for prophylaxis (4/17); management of contacts in transport vehicles (4/17); increased emphasis on contact with pharyngeal secretions as a criterion for defining close contact (1/17); and criteria for laboratory diagnosis $(1 / 17)$. Nine additional countries/regions stated they were planning to use the ECDC guidance document to update their country policy.

\section{Cross border communication}

In case of IMD occurring in a resident of another country, 28 of 32 countries/regions reported having a policy in place in 2013 for contacting the source country for contact tracing, if indicated. This was already the case for 19 out of 22 countries/regions in 2007.

\section{Discussion}

Comparison of the results of the 2007 [12] and 2013 surveys reveals increasing harmonisation of public health policies for the management of sporadic IMD cases and a relatively high level of adherence to evidence-based guidance as published by ECDC in the period between the two surveys $[10,13,14]$. This applied to the two laboratory diagnostic case definition criteria considered to be gold standard [10], meningococcal culture and DNA isolation from a sterile site, and, in particular, to the choice of antibiotics for PEP and their use in preschools, elementary and secondary schools, and universities. Recommendations for the management of contacts of an IMD case on transport vehicles remained heterogeneous, possibly reflecting the low level of evidence available in this area.

ECDC guidance $[10,13,14]$ emphasises that exposure to respiratory droplets or pharyngeal secretions of a case is essential for the transmission of meningococcal disease. Thus, a casual social contact, even if involving sharing drinks or cigarettes, is not in itself an indication for PEP [10]. Although not statistically significant, fewer countries/regions considered such contacts to warrant a recommendation for PEP in 2007 than in 2013. In addition, 'kissing on the mouth' was also considered by fewer countries/regions in 2013 than in 2007 to be a criterion for close contact. ECDC guidance states that exchange of pharyngeal secretions is likely to occur during intimate mouth-to-mouth kissing, which was found to be a risk factor for carriage or disease in observational studies [15-17]. However, a brief kiss on the mouth is unlikely to lead to significant exchange of pharyngeal secretions. Interpretation of our finding is difficult, as the wording of 'kissing on the mouth' was possibly interpreted to mean intimate mouth-to-mouth kissing by some, but not all countries/regions. Future surveys should define both types of kissing. In addition, we would like to stress that no contact indicator should be considered in isolation; rather, the overall contact history of each person must be evaluated to assess the likelihood of contact with pharyngeal secretions of the index case.

As concluded in the ECDC guidance [10], none of the recommended regimens (rifampicin, ciprofloxacin, ceftriaxone, azithromycin and cefixime) can be considered superior in terms of effectiveness to eradicate meningococcal carriage $[10,11]$. However, ciprofloxacin, azithromycin and ceftriaxone have the advantage of low reported rates of side effects and can be given as single dose, although the latter must be given intramuscularly [10]. Most countries/regions recommended ciprofloxacin and rifampicin, followed by ceftriaxone, 
TABLE 4

Use of post-exposure prophylaxis in IMD contacts in different educational settings, European survey on public health policies for managing cases of meningococcal disease and their contacts, 2013

\begin{tabular}{|c|c|c|c|c|c|}
\hline \multirow{2}{*}{\multicolumn{2}{|c|}{ Recommendation of chemoprophylaxis }} & \multirow{2}{*}{$\begin{array}{l}\text { Countries/regions applying } \\
\text { recommendation in } 2013 \\
(N=32)^{\text {a }} \\
n\end{array}$} & \multicolumn{2}{|c|}{$\begin{array}{l}\text { Countries/regions responding to both } \\
\text { surveys and applying recommendation } \\
2007(\mathrm{~N}=23) \text { and } 2013(\mathrm{~N}=23)\end{array}$} & \multirow[t]{2}{*}{$\begin{array}{l}\text { P value for comparison } \\
2007 \text { vs } 2013\end{array}$} \\
\hline & & & n (2007) & n (2013) & \\
\hline \multirow{4}{*}{ Preschool } & For all children & 5 & 3 & 2 & 1.0 \\
\hline & $\begin{array}{c}\text { for all children of the } \\
\text { same group }\end{array}$ & 22 & 8 & 17 & 0.02 \\
\hline & $\begin{array}{l}\text { For close contacts in } \\
\text { the same group }\end{array}$ & 1 & 0 & 1 & 1.0 \\
\hline & No chemoprophylaxis & 3 & 12 & 3 & 0.01 \\
\hline \multirow{4}{*}{$\begin{array}{l}\text { Elementary } \\
\text { school }^{\mathrm{b}}\end{array}$} & For all pupils & 0 & NA & NA & NA \\
\hline & $\begin{array}{c}\text { For all pupils in the } \\
\text { same class }\end{array}$ & 7 & NA & NA & NA \\
\hline & $\begin{array}{l}\text { For close contacts in } \\
\text { the same class }\end{array}$ & 17 & NA & NA & NA \\
\hline & No chemoprophylaxis & 7 & NA & NA & NA \\
\hline \multirow{4}{*}{$\begin{array}{l}\text { Secondary } \\
\text { school }^{\mathrm{b}}\end{array}$} & For all pupils & 0 & NA & NA & NA \\
\hline & $\begin{array}{c}\text { For all pupils attending } \\
\text { the same class }\end{array}$ & 6 & NA & NA & NA \\
\hline & $\begin{array}{l}\text { For close contacts in } \\
\text { the same class }\end{array}$ & 19 & NA & NA & NA \\
\hline & No chemoprophylaxis & 7 & NA & NA & NA \\
\hline \multirow{3}{*}{ University ${ }^{b}$} & $\begin{array}{c}\text { For all students of the } \\
\text { same class }\end{array}$ & 1 & NA & NA & NA \\
\hline & $\begin{array}{l}\text { For close contacts in } \\
\text { the same group }\end{array}$ & 25 & NA & NA & NA \\
\hline & No chemoprophylaxis & 6 & NA & NA & NA \\
\hline
\end{tabular}

ECDC: European Centre for Disease Prevention and Control; IMD: invasive meningococcal disease.

a Number of countries responding to the question on pre-, elementary and secondary school in 2013: $\mathrm{n}=32$; responding to questions on university settings: $n=33$.

b This criterion was not included in the 2007 questionnaire.

ECDC recommendations are highlighted in grey.

for adults. Despite rifampicin requiring four doses and being associated with the development of resistance [11], most countries/regions still recommended it. Only four countries/regions specifically recommended single-dose ciprofloxacin or azithromycin and not rifampicin for adults.

Rifampicin was the antibiotic most commonly recommended for children, followed by ceftriaxone, the recommendation for which significantly increased from 2007 to 2013. Ciprofloxacin was recommended for PEP in children by nine of 32 countries/regions in 2013, with little change since 2007. Although ciprofloxacin is considered safe in children [10], reluctance to use this antibiotic is likely related to the warning of a theoretical risk of arthropathy in children in the product information. In addition, 'chemoprophylaxis of IMD' is listed as an indication for adults, but not for children in the summary of product characteristics (SPC) for ciprofloxacin [18]. In contrast, rifampicin is licensed for prophylaxis of meningococcal disease at all ages [10]. While ceftriaxone is not explicitly licensed for meningococcal prophylaxis, it is widely used for treatment of IMD.
We are not aware that meningococcal prophylaxis is included as an indication in the SPC of the other antibiotics for which there is evidence that they eradicate meningococcal carriage (azithromycin, cefixime). This, together with a lower level of evidence for the use of these antibiotics for prophylaxis, likely explains why only few countries/regions recommended these at all. Although the effectiveness of azithromycin and cefixime were comparable to rifampicin each in one randomised controlled trial $[19,20]$, no trials compared these two antibiotics with placebo. In contrast, high eradication rates were shown for rifampicin, ciprofloxacin and ceftriaxone in various randomised placebocontrolled trials, providing a more robust evidence base [10]. Furthermore, while very low resistance rates have been reported for ciprofloxacin, rifampicin and ceftriaxone in European countries [1], routine sensitivity testing of $N$. meningitidis for azithromycin and cefixime has not been widely implemented. Thus there is a paucity of data regarding development of resistance against these antibiotics, with no such data reported by EARS (European Antimicrobial Resistance Surveillance; hosted by ECDC) thus far $[1,21]$. Some countries/ regions recommended rifampicin and ciprofloxacin for 
Criteria defining eligibility for post-exposure prophylaxis in countries/regions recommending chemoprophylaxis for fellow passengers of an IMD case on a plane, European survey on public health policies for managing cases of meningococcal disease and their contacts, 2013

\begin{tabular}{|c|c|c|c|c|}
\hline \multirow[t]{2}{*}{$\begin{array}{l}\text { Criteria for chemoprophylaxis in } \\
\text { fellow passengers on a plane }\end{array}$} & \multirow{2}{*}{$\begin{array}{l}\text { Countries/regions applying } \\
\text { criteria in } 2013 \\
(\mathrm{~N}=20)^{\mathrm{b}}\end{array}$} & \multicolumn{2}{|c|}{$\begin{array}{c}\text { Countries/regions responding to both surveys } \\
\text { and applying criteria } \\
2007(\mathrm{~N}=9)^{c} \text { and } 2013(\mathrm{~N}=13)^{c}\end{array}$} & \multirow[t]{2}{*}{$\begin{array}{l}\text { P value for comparison } \\
2007 \text { vs } 2013\end{array}$} \\
\hline & & n (2007) & n (2013) & \\
\hline \multicolumn{5}{|l|}{ Duration of travel } \\
\hline Four hours or more & 2 & 2 & 23 & 1.0 \\
\hline Seven hours or more & 1 & 1 & 0 & 0.41 \\
\hline Eight hours or more & 8 & 3 & 5 & 1.0 \\
\hline Overnight travel & 0 & 2 & 0 & 0.16 \\
\hline Time not taken into account ${ }^{d}$ & 9 & 1 & 6 & 0.17 \\
\hline \multicolumn{5}{|l|}{ Proximity to the case } \\
\hline Seated next to the case & 6 & 4 & 4 & 0.66 \\
\hline $\begin{array}{l}\text { Seated in the same row, row in } \\
\text { front/back }\end{array}$ & 7 & 1 & 4 & 0.61 \\
\hline $\begin{array}{l}\text { Contact with pharyngeal } \\
\text { secretions of the case }\end{array}$ & 5 & 1 & 4 & 0.61 \\
\hline Undefined & 2 & 3 & 1 & 0.26 \\
\hline
\end{tabular}

ECDC: European Centre for Disease Prevention and Control; IMD: invasive meningococcal disease; RAGIDA: Risk assessment guidelines for diseases transmitted on aircraft.

a Responses were free-text in the 2007 questionnaire and multiple choice in the 2013 version.

${ }^{b}$ Countries/regions recommending post-exposure prophylaxis to passengers with contact to an IMD case on a plane in $2013: \mathrm{n}=20 / 32$ (63\%).

' Countries/regions recommending post-exposure prophylaxis to passengers with contact to an IMD case on a plane; 2007 : $\mathrm{n}=9 / 22$ ( $41 \%$ ); 2013: $n=13 / 23$ (57\%).

${ }^{\mathrm{d}}$ For 2007: time criteria not mentioned by one country.

ECDC or RAGIDA recommendations are highlighted in grey.

pregnant women despite theoretical risk to the foetus based on animal studies. Although this risk is considered low, the use of ceftriaxone, cefixime and azithromycin in pregnancy is considered safer [10]. Finally, there is no supporting evidence to use antibiotics such as spiramycin, penicillin, cotrimoxazole and ofloxacin, still occasionally recommended for PEP in European countries [10].

The proportion of countries/regions recommending PEP in preschool settings increased significantly from 2007 to 2013. This is in agreement with the weak recommendation in the ECDC guidance to provide PEP to contacts in the same preschool group, depending on risk assessment, despite availability of only low-quality evidence $[10,22]$. In older children and students most countries/regions only recommended PEP to close contacts within the class, also in agreement with ECDC guidance.

In 2013, about two-thirds of countries/regions recommended PEP to contacts after a case on a plane in various circumstances. Risk of transmission of meningococcal disease on airplanes is generally low [13] and sharing the same transport vehicle as an IMD case should not in itself justify PEP $[10,14]$. As in other settings, contact with pharyngeal secretions of a case qualifies for the administration of chemoprophylaxis, yet this criterion played a role in only one quarter of countries/regions' recommendations concerning air travel. However, RAGIDA does state that, based on expert opinion and given the severity of the disease, contact tracing can be considered for persons sitting next to the suspected or laboratory-confirmed case [13].

In spite of a strong recommendation for post-exposure vaccination for serogroups $A, C, W$ and $Y$ in addition to PEP $[7,10], 10$ of 34 countries/regions did not have a respective policy in place, with little change from 2007 to 2013. This may be due to the very low level of evidence behind this recommendation [10].

Communication between countries/regions in case of transborder IMD case management is an important issue given the steadily increasing mobility throughout Europe. Almost $90 \%$ of countries/regions reported having a policy in place ensuring such communication. In addition, a high level of adherence to ECDC guidance in many areas - as observed in the 2013 survey - facilitates this task.

ECDC guidance on public health management of sporadic IMD was found useful by most participating countries/regions at the national level. However, only half of the countries/regions used the guidance to change 
recommendations. Besides, some of these countries having most recommendations already in place, a possible explanation is that the time interval between publication of the guidance and the survey was less than three years and may have been insufficient to achieve changes in national policies. This could explain persistence of significant discrepancies between country recommendations, for instance in the management of contacts in schools and public transport vehicles and the vaccination of close contacts. It is likely that practical issues, policy constraints related to use of antibiotics, reluctance to recommend antibiotics not explicitly licensed for PEP as well as economic considerations continue to contribute to these residual differences. In addition, some countries/regions may view recommendations based on very low levels of evidence more critically than others; however, it is unlikely that higher level of evidence will be obtainable in most of these areas, as the very large studies that would be required are not feasible in a setting of overall low disease incidence. Nonetheless, increasing awareness of available evidence, for instance through translation of guidance documents into the respective languages, might improve adherence. It is also possible that the overall low incidence in European countries/regions may partly explain reluctance to adopt recommendations that contribute with relatively low effectiveness to prevention of subsequent cases in the same setting. For instance, it has been estimated that to prevent one subsequent case, PEP must be administered to 300 household contacts, but to 1,900 same-group preschool contacts [10], and ca 1,000 household contacts need to be vaccinated [7].

There may be other reasons for persistent differences as well, such as logistic and economic considerations related to the structure of a particular healthcare system that might influence the feasibility of implementing certain public health measures even when recommended by international guidance. For instance, some antibiotics are more expensive than others or might be centrally procured at a reduced rate, and postexposure vaccination can be logistically challenging as vaccination may not be performed by the public health authority making the recommendation. Furthermore, countries may be reluctant to recommend antibiotics without routine resistance testing. All of these factors should be addressed in future similar surveys.

Comparisons between the two surveys were limited by the smaller number of countries/regions that participated in 2007. Nonetheless, comparability between the surveys was high due to the similar method used and their being undertaken by almost the same team. The respective participants gave us information on the official national policy of their countries/regions. However, we could not assess to what extent policies were legally binding and actually implemented in the respective country. We tried to address this by carefully identifying the person best placed to participate for each country. Further research on the actual implementation of recommendations would be useful.

In conclusion, public health policies for the management of sporadic IMD cases were better harmonised among European countries/regions in 2013 compared with 2007 . This is notably reflected by good adherence to evidence-based recommendations regarding the most important target groups requiring PEP as well as the choice of antibiotics for PEP published in 2010, suggesting that guidance disseminated by an international public health agency can have an important impact on public health policy. However, some discrepancies remained, e.g. only a minority of countries/ regions strictly followed ECDC guidance for IMD contacts in airplanes. Future surveys should specifically aim to identify possible reasons for persistent discrepancies in public health management of IMD that might help achieve further harmonisation, as this is desirable in the context of increasing mobility across European societies.

\section{Acknowledgements}

We would like to thank all participating IMD experts without whom this survey would not have been possible: Austria, Sigrid Heuberger; Belgium, Valeska Laisnez and Carole Schirvel; Bulgaria, Teodora Georgieva; Croatia, Sanja Kurečić Filipović; Cyprus, Maria Koliou; Czech Republic, Pavla Křžzová; Denmark, Palle Valentiner-Branth; Estonia, Natalia Kerbo; Finland, Markku Kuusi; France, Isabelle Parent du Chatelet; Germany, Wiebke Hellenbrand; Greece, Georgina Tzanakaki and Theano Georgakopoulou; Hungary, Katalin Krisztalovics; Iceland, Thorolfur Gudnason; Ireland, Suzanne Cotter; Italy, Fortunato D’Ancona; Latvia, Irina Lucenko; Liechtenstein, Sabine Erne; Lithuania, Egle Pauzaite; Luxembourg, Pierre Weicherding; Malta, Jackie Maistre Melillo; Netherlands, Aura Timen; Norway, Hans Blystad; Poland, Iwona Paradowska-Stankiewicz; Portugal, Ana Leça; Romania, Lavinia Cipriana Zota; Slovakia, Maria Avdičová; Slovenia, Alenka Kraigher; Spain, Rosa Cano; Sweden, Tiia Lepp; Switzerland, Elisabetta Peduzzi; United Kingdom, Shamez Ladhani.

\section{Conflict of interest}

None declared.

\section{Authors' contributions}

Sabine Vygen: protocol writing, carrying out of the survey, data analysis and writing up of the manuscript;

Wiebke Hellenbrand and Pawel Stefanoff: discussions and scientific input on protocol, data analysis and manuscript;

Germaine Hanquet, Sigrid Heuberger, and James Stuart: scientific input on protocol and manuscript.

References

1. European Centre for Disease Prevention and Control (ECDC). Surveillance of invasive bacterial diseases in Europe, 2011. Stockholm: ECDC; 2013. Available from: http://www.ecdc.europa. eu/en/ 
publications/_layouts/forms/Publication_DispForm. aspx? List $=4$ f55ad51-4aed-4d32-b960-af70113dbb90\&ID $=994$.

2. Heymann DL. Control of communicable disease manual, nineteenth edition. American Public Health Association, 2008.

3. Bettinger JA, Scheifele DW, Le Saux N, Halperin SA, Vaudry W, Tsang R, et al. The disease burden of invasive meningococcal serogroup $B$ disease in Canada. Pediatr Infect Dis J. 2013;32(1):e20-5. Available from: DOI: 10.1097/ INF.ob013e3182706b89 PMID: 22926207

4. Viner RM, Booy R, Johnson H, Edmunds WJ, Hudson L, Bedford $\mathrm{H}$, et al. Outcomes of invasive meningococcal serogroup $\mathrm{B}$ disease in children and adolescents (MOSAIC): a case-control study. Lancet Neurol. 2012;11(9):774-83. DOI: 10.1016/S14744422(12)70180-1 PMID: 22863608

5. European Centre for Disease Prevention and Control (ECDC). Surveillance of invasive bacterial diseases in Europe 2008/2009. Stockholm: ECDC; 2011. Available from: http:// ecdc.europa.eu/en/publications/Publications/1107_SUR_ IBD_2008-09.pdf

6. Hastings L, Stuart J, Andrews N, Begg N. A retrospective survey of clusters of meningococcal disease in England and Wales, 1993 to 1995: estimated risks of further cases in household and educational settings.Commun Dis Rep CDR Rev. 1997;7(13):R195-200.

7. Hoek MR, Christensen H, Hellenbrand W, Stefanoff P, Howitz M, Stuart JM. Effectiveness of vaccinating household contacts in addition to chemoprophylaxis after a case of meningococcal disease: a systematic review. Epidemiol Infect. 2008;136(11):1441-7.

8. De Wals P, Hertoghe L, Borlée-Grimée I, De Maeyer-Cleempoel S, Reginster-Haneuse G, Dachy A, et al. Meningococcal disease in Belgium. Secondary attack rate among household, day-care nursery and pre-elementary school contacts. J Infect. 1981;3(1) Suppl;53-61. Available from: DOI: 10.1016/S01634453(81)80009-6 PMID: 7185953

9. Munford RS, Souza De Morais J, De EA, Taunay AE, Fraser DW, Feldman RA. Spread of meningococcal infection within households.Lancet. 1974;303(7869):1275-8. Available from: DOI: 10.1016/S0140-6736(74)90022-1 PMID: 4134961

10. European Centre for Disease Prevention and Control (ECDC). Public health management of sporadic cases of invasive meningococcal disease and their contacts. Stockholm: ECDC; 2010. Available from: http://ecdc.europa.eu/en/publications/ Publications/1010_GUI_Meningococcal_guidance.pdf

11. Zalmanovici Trestioreanu A, Fraser A, Gafter-Gvili A, Paul $M$, Leibovici L. Antibiotics for preventing meningococcal infections.Cochrane Database Syst Rev. 2011; (8):CDo04785. DOI: 10.1002/14651858.CDo04785.pub4 PMID: 21833949

12. Hoek M, Hanquet G, Heuberger S, Stefanoff P, Zucs P, Ramsay $M$, et al. A European survey on public health policies for managing cases of meningococcal disease and their contacts. Euro Surveill. 2008;13(10):8060.PMID: 18445439

13. European Centre for Disease Prevention and Control (ECDC). ECDC technical report. Risk assessment guidelines for infectious diseases transmitted on aircraft. Stockholm: ECDC; 2009. Available from: http://www.ecdc.europa.eu/ en/publications/publications/0906_ter_risk_assess ment guidelines_for_infectious_diseases_transmitted_on_aircraft. pdf

14. European Centre for Disease Prevention and Control (ECDC). Risk assessment guidelines for diseases transmitted on aircraft. PART 2: Operational guidelines for assisting in the evaluation of risk for transmission by disease. Stockholm: ECDC; 2010. Available from: http://ecdc.europa.eu/ en/ publications/publications/1012_gui_ragida_2.pdf

15. Stanwell-Smith RE, Stuart JM, Hughes AO, Robinson $P$, Griffin MB, Cartwright K. Smoking, the environment and meningococcal disease: a case control study. Epidemiol Infect. 1994;112(02):315-28. Available from: DOI: 10.1017/ So950268800057733 PMID: 8150006

16. United Kingdom Meningococcal Carriage Group, MacLennan J, Kafatos G, Neal K, Andrews N, Cameron JC, Roberts R, et al. . Social behavior and meningococcal carriage in British teenagers.Emerg Infect Dis. 2006;12(6):950-7. Available from: DOI: 10.3201/eid1206.051297 PMID: 16707051

17. Tully J, Viner RM, Coen PG, Stuart IM, Zambon M, Peckham C, et al. Risk and protective factors for meningococcal disease in adolescents: matched cohort study. BMJ. 2006;332(7539):44550. Available from: DOI: $10.1136 / \mathrm{bmj} .38725 .728472$. BE PMID: 16473859

18. European Medicines Agency (EMA). 2008. Summary of product characteristics for Ciprofloxacin Bayer and associated names. London: EMA. [Accessed 30 Mar 2015]. Available from: http://www.ema.europa.eu/docs/en_GB/document_library/ Referrals_document/Ciprofloxacin_Bayer_30/WC500008075. pdf
19. Girgis N, Sultan Y, Frenck RW, El-Gendy A, Farid Z, Mateczun A. Azithromycin compared with rifampin for eradication of nasopharyngeal colonization by Neisseria meningitidis. Pediatr Infect Dis J. 1998;17(9):816-9. DOI: 10.1097/00006454199809000-00013 PMID: 9779768

20. Podgore JK, Girgis N, El-Refai M, Abdel-Monheim A. A doubleblind randomized trial of cefixime compared to rifampin in the eradication of meningococcal pharyngeal carriage in a closed population.J Trop Med (Cairo). 1993;2(5):41-5.

21. European Centre for Disease Prevention and Control (ECDC). Antimicrobial resistance surveillance in Europe 2013. Annual Report of the European Antimicrobial Resistance Surveillance Network (EARS-Net). Stockholm: ECDC; 2014. Available from: http://ecdc.europa.eu/en/publications/Publications/ antimicrobial-resistance-surveillance-europe-2013.pdf

22. Hellenbrand W, Hanquet G, Heuberger S, Nielsen S, Stefanoff $P$, Stuart JM. What is the evidence for giving chemoprophylaxis to children or students attending the same preschool, school or college as a case of meningococcal disease?Epidemiol Infect. 2011;139(11):1645-55. Available from: DOI: 10.1017/ So950268811001439 PMID: 21835067

23. Andrews J, Guyatt G, Oxman AD, Alderson P, Dahm P, FalckYtter Y, et al. GRADE guidelines: 14 . Going from evidence to recommendations: the significance and presentation of recommendations. J Clin Epidemiol. 2013;66(7):719-25.

\section{License and copyright}

This is an open-access article distributed under the terms of the Creative Commons Attribution (CC BY 4.0) Licence. You may share and adapt the material, but must give appropriate credit to the source, provide a link to the licence, and indicate if changes were made.

This article is copyright of the authors, 2016. 